This item was submitted to Loughborough's Research Repository by the author.

Items in Figshare are protected by copyright, with all rights reserved, unless otherwise indicated.

\title{
In-cylinder friction reduction using a surface finish optimization technique
}

PLEASE CITE THE PUBLISHED VERSION

http://dx.doi.org/10.1243/09544070JAUTO282

PUBLISHER

Professional Engineering Publishing / @ IMECHE

VERSION

VoR (Version of Record)

LICENCE

CC BY-NC-ND 4.0

REPOSITORY RECORD

Rahnejat, Homer, Sashi Balakrishnan, P.D. King, and S.J. Howell-Smith. 2019. "In-cylinder Friction Reduction Using a Surface Finish Optimization Technique". figshare. https://hdl.handle.net/2134/4744. 
This item was submitted to Loughborough's Institutional Repository (https://dspace.lboro.ac.uk/) by the author and is made available under the following Creative Commons Licence conditions.

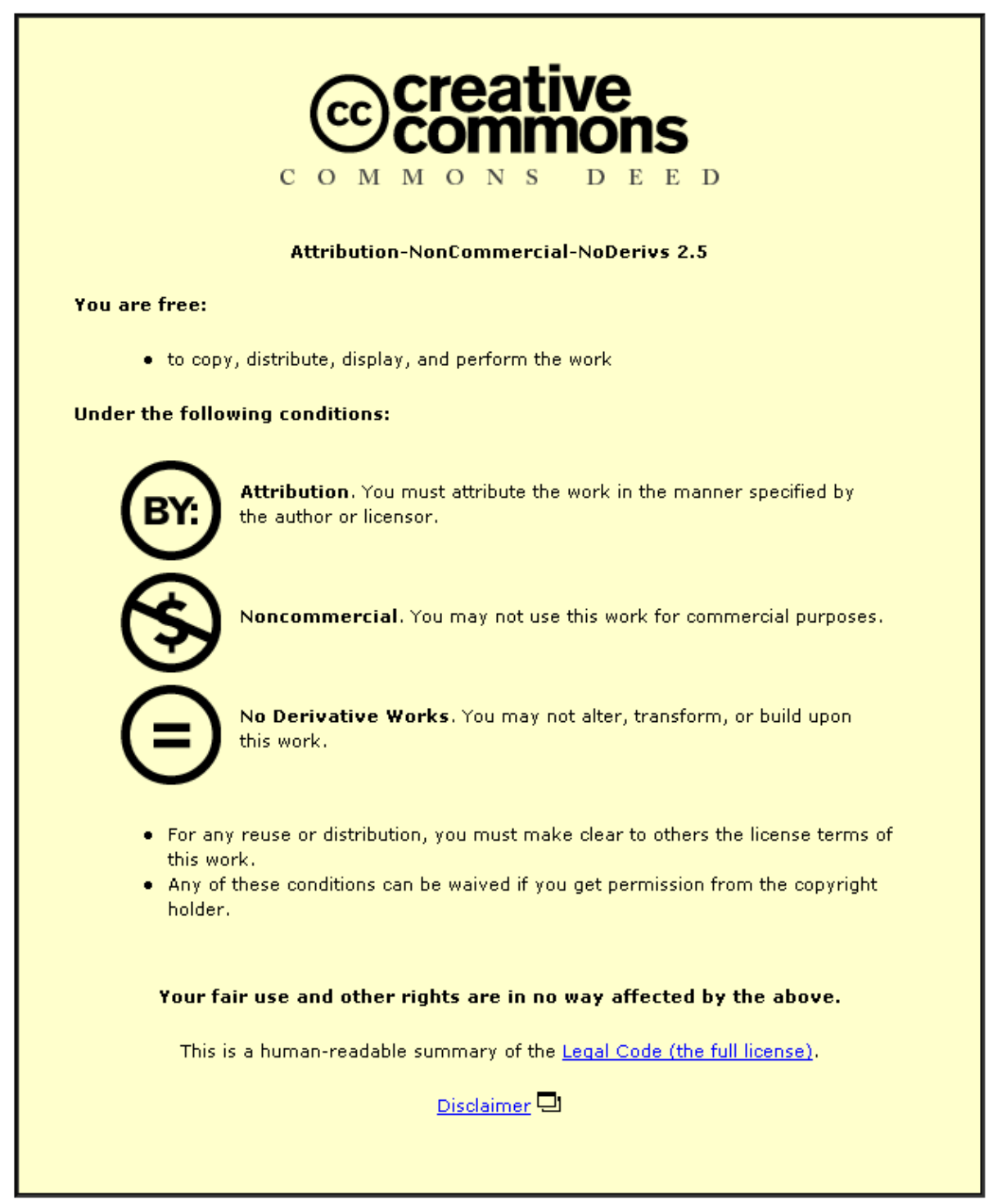

For the full text of this licence, please go to: http://creativecommons.org/licenses/by-nc-nd/2.5/ 


\title{
In-cylinder friction reduction using a surface finish optimization technique
}

H Rahnejat $^{1 *}$, S Balakrishnan ${ }^{1}$, P D King ${ }^{1}$, and S Howell-Smith ${ }^{2}$

${ }^{1}$ Wolfson School of Mechanical and Manufacturing Engineering, Loughborough University, Loughborough,

Leicestershire, UK

${ }^{2}$ Perfect Bore Ltd, Andover, UK

The manuscript was received on 9 February 2006 and was accepted after revision for publication on 6 April 2006.

DOI: 10.1243/09544070JAUTO282

\begin{abstract}
The paper describes the importance of reducing frictional losses in internal combustion (IC) engines, thereby improving engine efficiency. One of the main sources contributing significantly to engine friction is the interaction between the piston compression and oil rings and the cylinder bore/liner. Improving the tribological performance in these conjunctions has the greatest potential for performance improvement in the IC engine. Traditionally, the approaches used to tackle this problem have relied heavily on empirical engineering judgement. These have resulted in many inconclusive studies, involving a large number of alternatives, including the introduction of cylinder liners with surface modification work and/or with special coatings. This paper highlights a fundamental investigation of surface modification and coating and its impact on frictional performance. The study combines numerical and experimental approaches. Very good agreement is found between the conclusions of numerical predictions and those of engine test bed work.
\end{abstract}

Keywords: internal combustion engines, in-cylinder friction, advanced cylinder liners, coatings (Nikasil, DLC), surface modification (laser etching)

\section{INTRODUCTION}

The piston-connecting rod-crank assembly is a complex transient multiphysics system, something that has not always been appreciated in the domainspecific studies reported in the literature. These domain-specific investigations have been dominated by the system performance in combustion, inertial dynamics, contact mechanics, and tribology. However, it is clear that these physical phenomena strongly interact and determine the ultimate performance of the system [1]. Although the behaviour of the system as a whole may be regarded as cyclic, the transient behaviour within each cycle of piston motion gives rise to significantly varying conditions [2]. Therefore, system performance in terms of mechanical losses

* Corresponding author: Wolfson School of Mechanical and Manufacturing Engineering, Loughborough University, Loughborough, LeicestershireLE11 3TU,UK.email: h.rahnejat@ lboro.ac.uk due to inertial imbalance, component deformation, and vibration, and frictional losses due to the interactions of contiguous solids in contact, vary during each cycle. This means that palliations sought should also be of a different nature, in accordance with the instantaneous prevailing conditions. For instance, where the reversals in motion of the piston occur at the top and bottom dead centres (TDC and BDC), lubricant entrainment into the contacts between the piston and the cylinder by the well-established wedge effect ceases $[3,4]$. Therefore, the resulting depletion of a lubricant film leads to excessive friction and wear.

In these locations, any residual lubricant film would be retained by three possible mechanisms:

(a) lubricant entrapment due to local surface topography;

(b) squeeze-film action due to localized deformation;

(c) rapid replenishment as a function of piston velocity. 
The last of these is a function of piston stroke and operating speed, which improves with higherperformance engines. Nevertheless, cessation of entraining motion of lubricant takes place and diminution of a film is a strong possibility. For a given engine configuration, the first two mechanisms would account for the remedial actions that can be undertaken.

Squeeze-film action is a result of the convergence of contact surfaces under load. This mechanism is now well understood, at least in a theoretical manner $[\mathbf{5}, \mathbf{6}]$. As the bodies approach, the lubricant tends to be pushed out of the contact. However, the rate of approach is usually greater than the viscous flow of lubricant out of the contact area. Consequently, with sufficient contact load, high enough pressures are generated in the lubricant film theoretically to deform the contiguous surfaces and thus form a film and inhibit the interaction of surface asperities. Therefore, the transient inertial dynamics of the system, as well as the elasticity of the bodies in contact, plays an important role, yielding a contact/impact force to create the localized deformation (referred to as the squeeze cave) [7]. The problem is the generation of such a contact force at TDC and BDC and its other unwanted implications, such as the slapping action.

The secondary motion of the piston (its coupled tilt about the axis of the gudgeon pin and lateral oscillations within the confines of its clearance with the cylinder) is the main source of generation of contact/impact force and moment (see Fig. 1). Note that the primary motion of the piston is along the axis of the cylinder. The contact/impact forces are generated by the inertia of the system and the combustion gas force, as briefly outlined later. To effect squeeze caving, the contact force would need to be of sufficient magnitude, and the area of contact would need to be diminished in order to cause localized elastic deformation at the positions of reversal. This was the case some two decades ago, where the peak combustion pressure coincided with the piston at TDC. One adverse implication of this was the slapping noise radiated from the cylinder block, which was at least considered as a sign of poor quality.

With low side forces, it is also difficult to encourage a viscous action of the lubricant, this being a desired rise in its viscosity, that would incline it to act as an incompressible amorphous solid. However, this is precisely one of the two desired outcomes, the other being surface geometries that encourage its entrapment $[\mathbf{1}, \mathbf{8}]$. Thus, from a tribological viewpoint, and in the absence of a sufficient contact load, rough contacting surfaces with a piezoviscous lubricant behaviour would be favoured. This, of course, is precisely the opposite to the perception of much of the problem in industry, particularly for highperformance engines. The lubrication at both TDC and BDC and in their immediate vicinities follows a mixed regime, where a very thin hydrodynamic film is interrupted by asperity contacts. The conditions that promote this hydrodynamic film are not favourable, not only because of the reversal effect but also
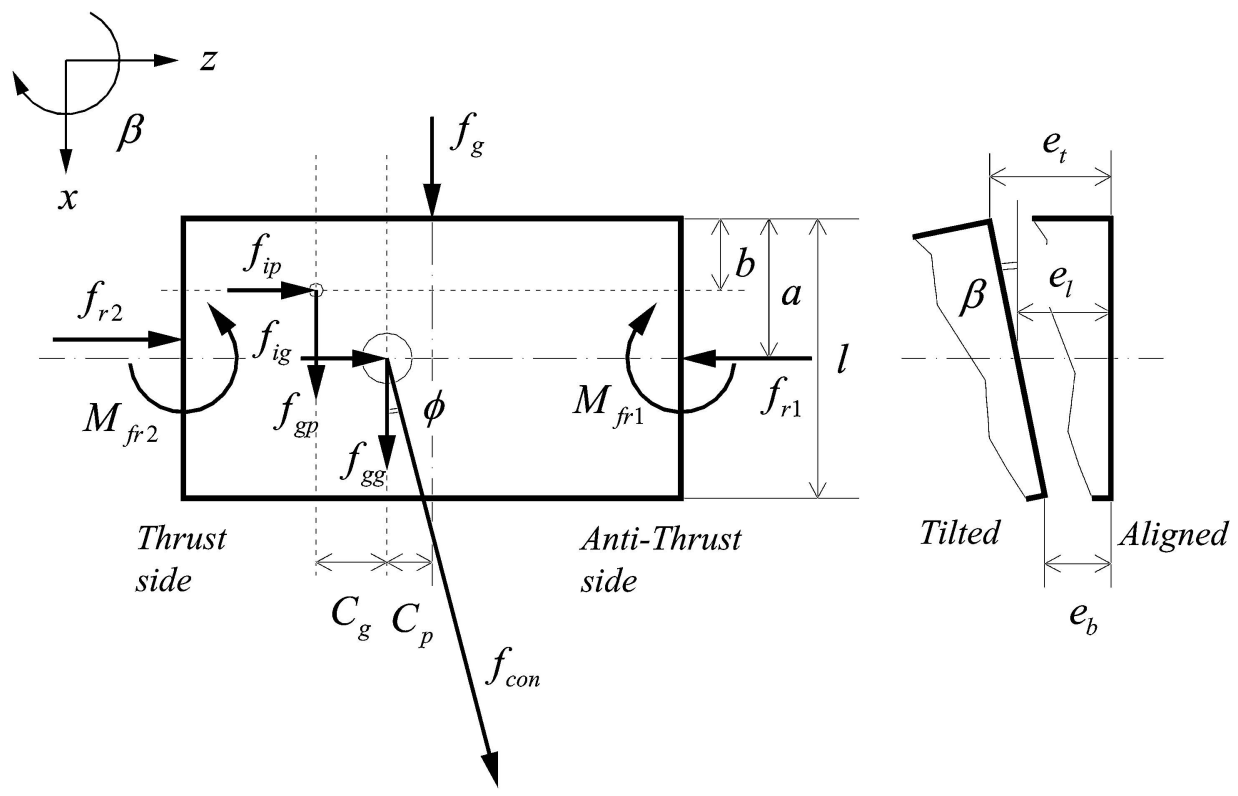

Fig. 1 Forces acting on the piston 
because of the lack of sufficient supply of lubricant ahead of the contact (i.e. lack of fully flooded condition).

For racing engines, the prevailing trend has been the introduction of cylinder liners of sufficient thickness to withstand the applied forces but allow localized deformation. However, with the realization that the prevailing conditions are largely hydrodynamic (i.e. insufficient pressures to cause localized deformation) or mixed lubrication, the trend has been to produce superfinish liners thus thought to prevent the incidence of asperity interactions as far as possible. The cost of manufacture has therefore increased substantially, but engine tests have shown little reduction in frictional losses. Furthermore, the use of liners of lower elastic moduli has resulted in greater thermal distortion, yielding better contact conformance and thus larger contact areas with increased surface interactions and friction. These few examples point to the rather incremental experiential approach, which has often been quite counterproductive.

For high-performance racing engines, where the element of cost is a lower objective than for the OEM, recent attempts have been made to modify cylinder liners by a combination of coating and surface modification [9]. However, the plethora of perceived options has led to inconclusive results, mainly based on accelerated tests on engine test beds. It has become clear that this traditional approach must be combined with detailed numerical analysis to arrive at an objective assessment of this multivariate problem. This paper highlights such a detailed systematic approach.

\section{THEORETICAL ANALYSIS}

A comprehensive numerical analysis of the problem is first undertaken. This involves the combined solution for the dynamics of the piston-connecting rod-crank subsystem, together with tribological interactions between the piston and the cylinder liner at the thrust and antithrust sides. This combined analysis is referred to as the tribodynamics of piston-cylinder interactions, and is detailed in references [6] and [8]. Here, an overview of the method used, together with details of the various advanced cylinder liners, is given.

The inertial dynamics of the piston is composed of its primary and secondary motions described in section 1 and depicted in Fig. 1. These are dependent on the instantaneous kinetic balance arising from the applied gas force, inertial forces, and the contact forces with the thrust and antithrust sides. The equations of motion can therefore be obtained as

$$
\begin{aligned}
& {\left[\begin{array}{cc}
m_{\mathrm{g}}\left(1-\frac{a}{l_{\mathrm{p}}}\right)+m_{\mathrm{p}}\left(1-\frac{b}{l_{\mathrm{p}}}\right) & m_{\mathrm{g}} \frac{a}{l_{\mathrm{p}}}+m_{\mathrm{p}} \frac{b}{l_{\mathrm{p}}} \\
\frac{I_{\mathrm{p}}}{l_{\mathrm{p}}}+m_{\mathrm{p}}(a-b)\left(1-\frac{b}{l_{\mathrm{p}}}\right) & m_{\mathrm{p}}(a-b) \frac{b}{l_{\mathrm{p}}}-\frac{I_{\mathrm{p}}}{l_{\mathrm{p}}}
\end{array}\right]} \\
& \times\left[\begin{array}{c}
\ddot{e}_{\mathrm{t}} \\
\ddot{e}_{\mathrm{b}}
\end{array}\right]=\left[\begin{array}{c}
f_{\mathrm{r} 1}+f_{\mathrm{r} 2}+f_{\mathrm{s}} \\
m_{\mathrm{fr} 1}+m_{\mathrm{fr} 2}+m_{\mathrm{s}}
\end{array}\right]
\end{aligned}
$$

where

$$
f_{\mathrm{s}}=\left(f_{\mathrm{gp}}+f_{\mathrm{gg}}+f_{\mathrm{g}}\right) \tan \phi
$$

and

$$
m_{\mathrm{s}}=f_{\mathrm{g}} C_{\mathrm{g}}-f_{\mathrm{gp}} C_{\mathrm{p}}
$$

Thus, the secondary motions of the piston in tilting, $\beta$, and lateral excursions, $e_{1}$, are replaced with the deviation of the piston at its top, $e_{\mathrm{t}}$, and at its bottom, $e_{\mathrm{b}}$, from the centre-line of the cylinder in the equations of motion. These relations are

$$
e_{\mathrm{t}}=e_{1}+a \beta
$$

and

$$
e_{\mathrm{b}}=e_{1}-\left(l_{\mathrm{p}}-a\right) \beta
$$

The primary (axial) motion of the piston is kinematic (i.e. is predetermined by the relationship between the crank rotation and piston motion). This is obtained in terms of the various engine order response characteristics, in this case up to and including the eighth engine order. Thus, a relationship of the following form is used

$$
\begin{array}{r}
\dot{x}=r \sin \omega t-\Psi_{i} \cos (2 \mathrm{i}-1) \omega t+\Psi_{i-1} \sin 2 \mathrm{i} \omega t \\
i=1, \ldots, 4
\end{array}
$$

where $\Psi_{i}=f\left(r, l, C_{\mathrm{p}}\right)$, the derivation of which is provided in reference [6].

The solution for secondary inertial dynamics is obtained by imposing a convergence criterion for $\ddot{e}_{\mathrm{t}}$ and $\ddot{e}_{\mathrm{b}}$ in equation (1), in this case

$$
\begin{aligned}
& \left|\frac{\ddot{e}_{\mathrm{t}, n}-\ddot{e}_{\mathrm{t}, n-1}}{\ddot{e}_{\mathrm{t}, n}} \times 100\right|<1 \\
& \left|\frac{\ddot{e}_{\mathrm{b}, n}-\ddot{e}_{\mathrm{b}, n-1}}{\ddot{e}_{\mathrm{b}, n}} \times 100\right|<1
\end{aligned}
$$

However, it is clear that this is only possible if the kinetic balance on the right-hand side of equation (1) 
is known at any instant of time. The applied forces on the piston and the gudgeon pin are derived from the combustion pressure. This leaves the determination of the contact forces and moments: $f_{\mathrm{r} k}$, $m_{\mathrm{fr} k}, k=1,2$. In this analysis, the moment loading of contacts has been ignored, and thus $m_{\mathrm{r} k}=0$, for $k=1,2$, and

$$
f_{\mathrm{r} k}=\iint_{i j} p_{i j} \mathrm{~d} x \mathrm{~d} y, \quad k=1,2
$$

where the pressure distribution $p_{i j}$ is assumed to be due to the lubricated contact between the piston and the cylinder liner. The method used to determine this is fully described in reference [6] and is briefly highlighted here.

To obtain the pressure distribution, $p_{i j}$, used in equation (8), the lubricant film thickness in the contact conjunctions between the piston and the cylinder liner on the thrust and antithrust sides are required. The films formed in these contacts are a function of the initial clearance, $c$, the approach of the piston towards the liner in lateral motion and tilt, and any elastic deformation of the contiguous solids as a result of the generated contact pressures. Ignoring the diminishing gap as the result of any thermal distortion (i.e. an isothermal solution), the film thickness is therefore obtained as

$$
h_{i j}=c+d_{i j}+s_{i j} \tan \beta+\delta_{i j}
$$

The elastic film shape equation (9) differs from that given in reference [6] in the inclusion of the parameter $d_{i j}$, which takes into account the depth of the laser-etched feature into the surface of the cylinder liner. This follows a spiral-type staggered pattern. The actual pattern is optimized to yield favourable lubricant retention capability. As the actual patterns are proprietary and commercially sensitive information, an indicative example based on circular geometry is given below as

$$
\begin{aligned}
& d_{i j} \neq 0 \mid R_{m-1}^{2}<\in(i, j)<R_{m}^{2} \\
& \text { else } d_{i j}=0
\end{aligned}
$$

This means that for all computational grid points located within a circular spiral domain there exists a finite modified depth, otherwise a nominally smooth surface is assumed. Here, $R_{m}$ and $R_{m-1}$ are the localized radii of circumscribed circles of two subsequent laser-etched spirals. Therefore, the com- putational mesh required to solve the problem at any instant of time is considerably finer than that used in reference [6].

The contact deformation at any location is obtained as

$$
\delta_{M N}=\frac{2}{\pi E^{\prime}} \int_{-\tilde{a}}^{\tilde{a}} \int_{-\tilde{b}}^{\tilde{b}} p_{i j}\left[\frac{\mathrm{d} x_{1} \mathrm{~d} y_{1}}{\left[\left(y-y_{1}\right)^{2}\left(x-x_{1}\right)^{2}\right]^{1 / 2}}\right]
$$

where $\tilde{a}$ and $\tilde{b}$ are the limits of the contact determined by the zero pressure isobar during the iteration process for pressure convergence, where, according to the Reynolds boundary condition, all negative pressures are set to zero.

The undeformed profile of the piston skirt is given by $s_{i, j}$, and the clearance, $c$, can include the necessary variations to take into account the ovality of the cylinder bore or the liner, and in fact any surface modifications, as described later.

The corresponding generated pressure distribution is obtained by simultaneous solution of equation (9) with Reynolds' equation, taking into account the variations in lubricant viscosity and density as functions of evaluated pressures. This procedure and the method of solution are described fully in references [6] and [8]. The equations are

$$
\begin{array}{r}
\frac{\partial}{\partial x}\left(\frac{\rho h^{3}}{\eta} \frac{\partial p}{\partial x}\right)+\frac{\partial}{\partial y}\left(\frac{\rho h^{3}}{\eta} \frac{\partial p}{\partial y}\right) \\
\quad=12\left[u \frac{\partial}{\partial x}(\rho h)+\frac{\partial}{\partial t}(\rho h)\right]
\end{array}
$$

where

$$
u=\frac{1}{2} \dot{x}
$$

For the viscosity-pressure dependence [10]

$$
\eta=\eta_{0} \mathrm{e}^{\alpha p}
$$

and for the density-pressure dependence [11]

$$
\rho=\rho_{0}\left(1+\frac{0.6 p}{1+1.7 p}\right)
$$

\section{THEORETICAL PREDICTIONS}

The aim of the theoretical predictions is to undertake a comparative study between standard crosshatched (honed) superfinish cylinder liners for high-performance engines and those of identical material construction but with surface laser-etched profiles to retain a lubricant film through entrapment. It is now well established that the regime of 
lubrication alters through the piston cycle $[\mathbf{4}, \mathbf{6}, \mathbf{8}]$, and that conditions are at worst at piston reversal points (BDC and TDC) owing to the cessation of relative motion and low side forces. Therefore, the lubricant film thickness decreases, promoting a greater chance of asperity interactions and thus increased friction. The hypothesis is that, contrary to the belief that smooth surfaces promote reduced friction, the inclusion of laser-etched features actually improves lubricant film, which can reduce frictional losses. This hypothesis is initially subjected to the above-stated analysis method through detailed simulation. Later, in section 4 , the findings of this study are compared with a field study through rigorous engine tests.

The engine under consideration is described in section 4 . Both the cylinder liner and the piston are made of 4988 grade aluminium alloy, electrolytically plated with Nikasil (nickel with silicon carbide dispersion) with a typical thickness in the range $75-150 \mu \mathrm{m}$. The surface roughness of the liner and piston skirt, $R_{\mathrm{a}}$, is $0.2-0.3 \mu \mathrm{m}$, and that of the piston rings is $0.07 \mu \mathrm{m}$. The compression ring has a face width of $1.2 \mathrm{~mm}$ and a depth of $3.5 \mathrm{~mm}$, and is made of nitrided steel with a ring tension of $4 \mathrm{~N} / \mathrm{mm}$.

The contact force at TDC is $4800 \mathrm{~N}$ with a piston tilt of $0.085^{\circ}$ towards the major thrust side. A computational finite difference mesh of 230 by 110 (the former in the axis of the piston stroke) is employed to cover a small segment of the contact. The high computational mesh density is required to include the effect of surface features in the tribological study.
Figure 2 shows an oil-film contour of the compression ring-standard cylinder liner contact, occurring between abscissa positions 1 and 2.2 in the figure. The minimum predicted film thickness is $0.36 \mu \mathrm{m}$. The root mean square of the composite surface roughness of the contacting bodies is around $0.22 \mu \mathrm{m}$. This means that the ratio of film thickness to this roughness (referred to as the $\lambda$ ratio [7]) is around 1.64, indicating a mixed regime of lubrication, clearly with asperity contacts.

Figure 3 shows the same conditions for the case of a laser-etched liner. Note that the depth of etch retains lubricant as reservoirs which help sustain a better film thickness in the contact region. The minimum film is now increased to $0.56 \mu \mathrm{m}$. This now yields a $\lambda$ ratio of 2.55. Note that a ratio of 3 heralds full fluid film lubrication. Thus, the introduction of etching has improved the tribological conditions, contrary to the common perception.

As, in practice, a mixed regime of lubrication is prevalent at TDC and BDC and in their immediate vicinity (as already described above), wear-resistant coatings have been favoured by some in highperformance engines, and not only in the case of the liner but also for cam-follower pairs. The hypothesis made here, and the relatively low contact pressures due to the conforming nature of the contact, suggests that the use of hard coatings, such as diamond like coatings (DLC), should inhibit any chance of deformation even at high contact forces. If this hypothesis is to be held, then numerical predictions under the same conditions should yield oil-film contours with lower film thickness, which is the case



Fig. 2 Oil-film contours in the contact of the compression ring (circumferential segment $4.25 \mathrm{~mm}$ ) and the standard liner at TDC (contour levels in $\mu \mathrm{m}$ ) 




Fig. 3 Oil-film contours in the contact of the compression ring (circumferential segment $4.25 \mathrm{~mm}$ ) and a laser-etched liner at TDC (contour levels in $\mu \mathrm{m}$ )

shown in Fig. 4, indicating minimum films of the order of $0.017 \mu \mathrm{m}$, as compared with the case of laser-etched Nikasil liner with a minimum thickness of $0.56 \mu \mathrm{m}$.

To verify these findings of the numerical model, a series of experiments is carried out.

\section{EXPERIMENTAL SET-UP AND INSTRUMENTATION}

Figure 5 shows a $449 \mathrm{~cm}^{3}$ four-stroke, four-valve, single overhead camshaft, single-cylinder engine modified to accommodate cylinder liners. This is to ascertain



Fig. 4 Oil-film contours in the contact of the compression ring (circumferential segment $4.25 \mathrm{~mm}$ ) and a laser-etched DLC liner at TDC (contour levels in $\mu \mathrm{m}$ ) 


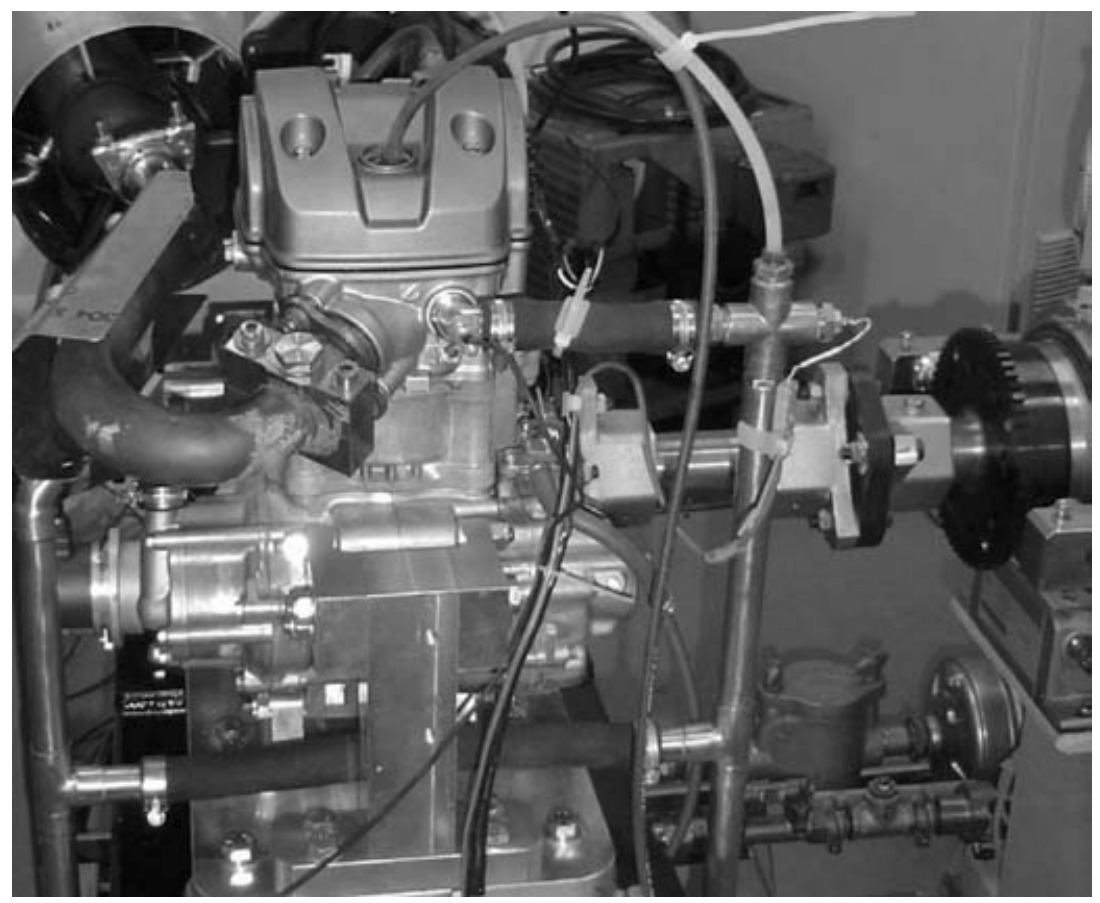

Fig. 5 Test engine

any performance gain (power and torque) with the advanced laser-etched liner (tribologically optimized) over the standard one. The unmodified engine has a high power output of $93 \mathrm{~kW} / 1$ (comparable with that of a high-performance racing engine). It produces nominally $37 \mathrm{~kW}$ at $9000 \mathrm{r} / \mathrm{min}$. The piston stroke is $64 \mathrm{~mm}$ and the bore diameter is $96 \mathrm{~mm}$. The skirt clearance is $150 \mu \mathrm{m}$. The engine is resisted by a transient a.c. dynamometer, which records the torque and output power at different engine speeds and throttle action. The engine is suitably instrumented to ensure repeatable and reproducible test conditions, as well as acquiring data required for the numerical analysis reported above. The output power is computed and corrected for any variations in test cell pressure, using a digital barometer and thermometer. The S3000 Ricardo Taskmaster logs all the above-mentioned data. A spark plug type Kistler pressure transducer and a digital crankshaft encoder are used to obtain the combustion pressure and crank position required to obtain forces $f_{\mathrm{g}}$ and $f_{\mathrm{gp}}$ in equation (3) (see Fig. 1).

\section{LINER CONFIGURATIONS}

Three cylinder liner configurations were tested. They were those described in section 3 :

(a) standard cross-hatched at $25-35^{\circ}$ to the horizontal plane, coated with Nikasil; (b) standard cross-hatched Nikasil with a laser-etched pattern;

(c) a DLC liner.

As already mentioned, the hypothesis, supported by the numerical findings described above, indicated that suitably laser-etched patterns on the surface of liners promote retention of film (see Fig. 6, showing a typical laser-etched liner).

Clearly, the groove patterns and their interspacing and depth are optimized through a number of simulation studies in order to maximize film thickness at reversal positions (TDC and BDC, where lubricant entrainment momentarily ceases). The study also guards against groove depths that can lead to oil loss. A brief description of the analysis is given in section 3 , with more details available in Balakrishnan et al. $[\mathbf{6}, \mathbf{8}]$. Here, results of engine tests in support of the methodology are provided.

The belief that a coherent film cannot be retained at the reversal points has led the high-performance engine industry to resort to the use of wear-resistant low-friction coatings such as DLC at a premium price. This is achieved through plasma coating. No evidence exists as to the effectiveness of DLC throughout a typical piston cycle relative to either a standard or laser-etched liner. Tribological know-how suggests that high elastic modulus coatings such as DLC would inhibit surface deformation due to contact forces, thus further reducing the chance of fluid film formation, although they may be more effective 


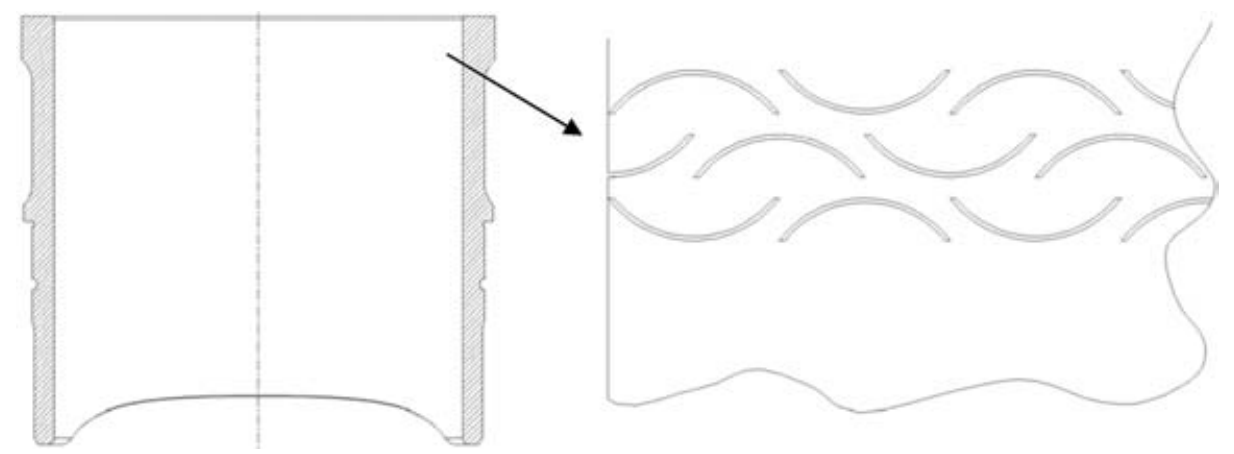

Fig. 6 Laser-etched cylinder liner

against onset of wear, where mixed or boundary lubrication is most likely (e.g. at TDC and BDC). Therefore, a DLC liner is also used in this study as an alternative.

\section{RESULTS AND DISCUSSION}

Figure 7 shows the variations in reference engine power output and torque with the standard liner. Note that the torque peak occurs at an engine speed of $6500 \mathrm{r} / \mathrm{min}$. Thereafter, the torque drops off as the power continues to increase at full throttle and peaks around $37 \mathrm{~kW}$. This baseline figure is used in the subsequent comparison between the standard liner and the others: DLC and laser-etched liners.

Figure 8 shows the percentage torque gained at various engine speeds at wide open throttle condition for the modified liners (DLC and laser-etched Nikasil) relative to the standard liner. Therefore, the datum condition represents the horizontal axis, which is the performance of the standard liner. It can be observed that the laser-etched liner shows a continual performance improvement of up to 4.5 per cent over the standard liner. The maximum benefit is at the peak torque of $6500 \mathrm{r} / \mathrm{min}$. This condition corresponds to the maximum contact force in the cylinder, where the localized deformation of the

Reference Engine Torque and Power Output



Fig. 7 Reference torque and power output 


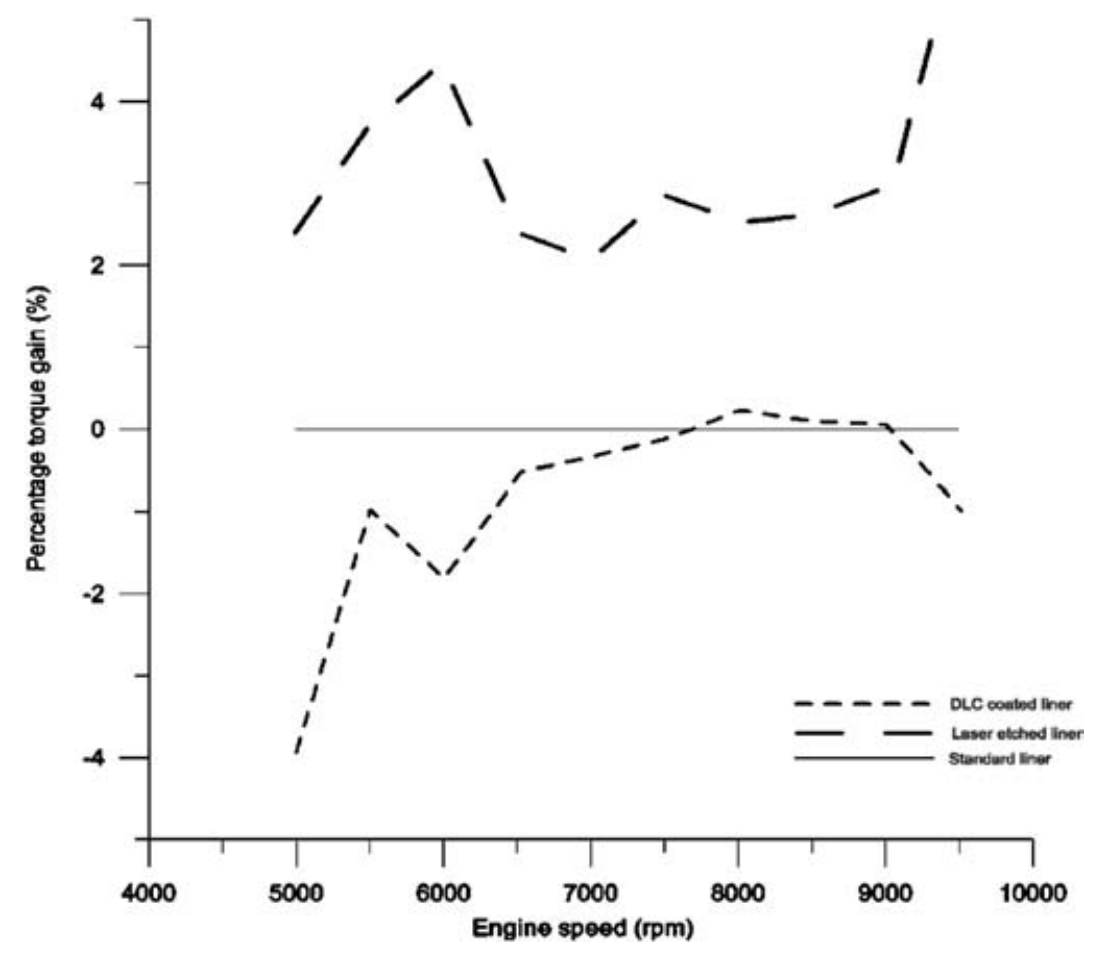

Fig. 8 Percentage torque relative power gain of modified liners over the standard liner

liner may result in a larger gap, and thus a thicker lubricant film. This is further enhanced by lubricant retention in the laser-etched grooves, as already indicated by the numerical results in Figs 2 to 4 .

Alternatively, with the DLC liner an inferior performance is observed throughout the speed range (see Fig. 8) with respect to the standard liner. Harder surfaces inhibit elastohydrodynamic lubrication conditions, thus forming a thinner film and a greater tendency towards a mixed lubrication regime, leading to increased asperity interactions and heat generation. This would result in shear thinning of the lubricant at higher speeds. Therefore, the smooth DLC surface should exhibit better frictional performance than the standard liner at higher speeds, with a small percentage gain relative to it, as indeed observed in Fig. 8.

\section{CONCLUSION}

The results obtained from the tests indicate the importance of this study and the benefit of using tribological optimization tools to reduce parasitic losses. Only careful modifications can yield beneficial results. The recent use of DLC in industry is misleading, because the preconception of a smooth and hard-wearing surface, yielding reduced frictional losses, is clearly proven not to be true for all applications.
Carefully optimized surface modification techniques, such as the localized laser etching described in this paper, have proven to be superior.

\section{ACKNOWLEDGEMENT}

The authors would like to express their gratitude to Perfect Bore Limited (Performance Motorsport Incorporated) for financial and technical support extended to this research project.

\section{REFERENCES}

1 Balakrishnan, S. and Rahnejat, H. Transient elastohydrodynamic lubrication of piston skirt to cylinder liner under combined reciprocating and slapping motions. 3rd AIMETA International Tribology Conference, Salerno, Italy, 2002.

2 Offner, G. and Priebsch, H. H. Elastic body contact simulation for predicting piston slap induced noise in an IC engine. in Multi-body dynamics: monitoring and simulation techniques - II (Eds H. Rahnejat and R. Whalley), 2000 (Mechanical Engineering Publications, London).

3 Li, D. F., Rhode, S. M., and Ezzat, H. A. An automotive piston lubrication model. ASLE Trans., 1982, 26, 151-160.

4 Oh, K. P., Li, C. H., and Goenka, P. K. Elastohydrodynamic lubrication of piston skirts. Trans. ASME, J. Tribology, 1987, 109, 356-362. 
5 Kushwaha, M. and Rahnejat, H. Transient elastohydrodynamic lubrication of finite line conjunction of cam to follower concentrated contact. J. Phys. D: Appl. Phys., 2002, 35(21), 2872-2890.

6 Balakrishnan, S. and Rahnejat, H. Isothermal transient analysis of piston skirt-to-cylinder wall contacts under combined axial, lateral and tilting motion. J. Phys. D: Appl. Phys., 2005, 38(5), 787-799.

7 Kushwaha, M. and Rahnejat, H. Transient concentrated finite line contact of roller to race under combined entraining, tilting and squeeze film motions. J. Phys. D: Appl. Phys., 2004, 37, 2018-2034.

8 Balakrishnan, S., Howell-Smith, S., Rahnejat, H., and Dowson, D. Investigation of reciprocating conformal contact of piston skirt and ring pack to cylinder liner under transient condition. 30th Leeds-Lyon Symposium, Lyon, September 2003.

9 Etsion, I. State of the art in laser surface. J. Tribology, 2005, 127(1), 248-253.

10 Barus, C. Isothermal, isopiestics and isometrics relative to viscosity. Am. J. Sci., 1893, 45, 87.

11 Dowson, D. and Higginson, G. R. The effect of material properties on the lubrication of elastic rollers. J. Mech. Engng Sci., 1960, 2.

\section{APPENDIX}

Notation

$a$

$b$

$C_{\mathrm{g}}$

$C_{\mathrm{p}}$

$d_{i j}$

$e_{\mathrm{b}}$

$e_{1}$

$e_{\mathrm{t}}$

$\ddot{e}_{\mathrm{b}}$

and liner $(\mathrm{m})$

offset of the centre of mass, measured

along the $z$ axis from the gudgeon (m)

offset of the gudgeon pin from the

centre-line (m)

etch depth (m)

lateral displacement of the lower end

of the piston skirt (m)

lateral displacement of the gudgeon

pin $(\mathrm{m})$

lateral displacement of the upper end

of the piston skirt (m)

lateral acceleration of the lower end of $\ddot{e}_{\mathrm{t}}$

$E^{\prime}$

$f_{\text {con }}$

$f_{\mathrm{g}}$

$f_{\text {gg }}$

$f_{\text {gp }}$

$f_{\text {ig }}$

$f_{\text {ip }}$

$f_{\mathrm{r} 1}$

$f_{\mathrm{r} 2}$

$h$

$I_{\mathrm{p}}$

$l_{\mathrm{p}}$

$m_{\mathrm{fr} 1}, m_{\mathrm{fr}}$

$m_{\mathrm{g}}$

$m_{\mathrm{p}}$

$p$

$s$

$t$

W

$x, y$

$\dot{x}$

$\alpha$ the piston skirt $\left(\mathrm{m} / \mathrm{s}^{2}\right)$ lateral acceleration of the upper end of the piston skirt $\left(\mathrm{m} / \mathrm{s}^{2}\right)$

effective modulus of elasticity of the

liner and piston $(\mathrm{Pa})$

connecting rod force $(\mathrm{N})$

gas force $(\mathrm{N})$

inertial force of the gudgeon owing to primary motion $(\mathrm{N})$

inertial force of the piston owing to primary motion $(\mathrm{N})$

inertial force of the gudgeon owing to secondary motion $(\mathrm{N})$

inertial force of the piston owing to

secondary motion $(\mathrm{N})$

reaction due to lubricant at the thrust

side $(\mathrm{N})$

reaction due to lubricant at the

antithrust side $(\mathrm{N})$

film shape $(\mathrm{m})$

piston inertia about its centre of mass

$\left(\mathrm{kg} \mathrm{m}^{2}\right)$

piston length (m)

hydrodynamic reaction moments

$(\mathrm{N} \mathrm{m})$

mass of the gudgeon pin $(\mathrm{kg})$

mass of the piston $(\mathrm{kg})$

generated lubricant pressure $(\mathrm{Pa})$

surface profile (m)

time (s)

speed of entraining motion $(\mathrm{m} / \mathrm{s})$

applied load $(\mathrm{N})$

Cartesian coordinates

piston velocity $(\mathrm{m} / \mathrm{s})$

pressure-viscosity of the lubricant $\left(\mathrm{m}^{2} / \mathrm{N}\right)$

tilt angle of the piston (rad)

elastic deformation (m)

dynamic viscosity at any pressure

(Pa s)

isothermal absolute atmospheric

dynamic viscosity (Pa s)

crank angle (rad)

lubricant density $\left(\mathrm{kg} / \mathrm{m}^{3}\right)$

lubricant density at atmospheric

condition $\left(\mathrm{kg} / \mathrm{m}^{3}\right)$

connecting rod angle (rad)

crankshaft angular velocity ( $\mathrm{rad} / \mathrm{s})$ 